\title{
Re: Oral vitamin A supplementation in very low birth weight neonates: a randomized controlled trial
}

\author{
Dnyanada Mhatre $^{1} \cdot$ Komal Agrawal $^{1} \cdot$ Haribalakrishna Balasubramanian ${ }^{1} \cdot$ Nandkishor Kabra $^{1}$
}

Received: 25 July 2019 /Revised: 25 July 2019 / Accepted: 8 August 2019 /Published online: 28 August 2019

(C) Springer-Verlag GmbH Germany, part of Springer Nature 2019

We read the RCT by Basu et al. [1] with great interest. Reduction in mortality or oxygen requirement in very low birth weight infants by supplementation of a simple, safe, cost-effective oral medication could be of tremendous clinical significance, especially for low- and middle-income countries. Their findings are further strengthened by the higher serum retinol concentrations on day 28 of treatment. However, we wish to raise certain issues and request few clarifications.

The authors assumed a baseline incidence of their primary outcome to be $64 \%$ whereas the observed incidence in the placebo group is only $25 \%$. Unfortunately, this has reduced the study's statistical power in detecting a true reduction in the rate of mortality or oxygen requirement at 28 days.

Majority of the deaths in the placebo group seem to have occurred within 7 days of age, as seen in the Kaplan-Meier survival curve. Could this result from not being exposed to vitamin A on alternate days? This also makes us think if there was a potential unmeasured confounder and whether the study groups were comparable at baseline. Adjustment of the primary outcome estimate for the competing risk event (early neonatal death) could have been considered.

Communicated by Peter de Winter

Haribalakrishna Balasubramanian

doctorhbk@gmail.com

Dnyanada Mhatre

drdnyanada06@gmail.com

Komal Agrawal

komal.softee@gmail.com

Nandkishor Kabra

nskabra@gmail.com

1 Surya Hospital, S V Road, Santacruz West, Mumbai, Maharashtra 400054, India
We would also be interested to know the number of infants discharged home before 28 days in both groups. Considering that vitamin A supplementation resulted in significant benefits among term neonates in community settings [2], the efficacy and safety of post-discharge vitamin A therapy in high-risk neonates need to be researched.

\section{Compliance with ethical standards}

Conflict of interest The authors declare that they have no conflict of interest.

Ethical approval This article does not contain any studies with human participants or animals performed by any of the authors.

\section{References}

1. Basu S, Khanna P, Srivastava R, Ashok K (2019) Oral vitamin A supplementation in very low birth weight neonates: a randomized controlled trial. Eur J Pediatr 178:1255-1265. https://doi.org/10. 1007/s00431-019-03412-w

2. Rahmathullah L, Tielsch JM, Thulasiraj RD, Katz J, Coles C, Devi S (2003) Impact of supplementing newborn infants with vitamin A on early infant mortality: community based randomised trial in southern India. BMJ 327:254-250

Publisher's note Springer Nature remains neutral with regard to jurisdictional claims in published maps and institutional affiliations. 